\title{
In vivo laser confocal microscopy findings of a cornea with osteogenesis imperfecta
}

This article was published in the following Dove Press journal:

Clinical Ophthalmology

2I February 20I4

Number of times this article has been viewed

\section{Akira Kobayashi \\ Tomomi Higashide \\ Hideaki Yokogawa \\ Natsuko Yamazaki \\ Toshinori Masaki \\ Kazuhisa Sugiyama}

Department of Ophthalmology, Kanazawa University Graduate School of Medical Science, Kanazawa, Japan

Correspondence: Akira Kobayashi Department of Ophthalmology, Kanazawa University Graduate School of Medical Science, I3-I Takara-machi, Kanazawa, Ishikawa-prefecture 920-864I, Japan

Tel +8I 762652403

Fax +8I 762229660

Email kobaya@kenroku.kanazawa-u.ac.jp
Objective: To report the in vivo laser confocal microscopy findings of a cornea with osteogenesis imperfecta (OI) with special attention to the abnormality of Bowman's layer and sub-Bowman's fibrous structures (K-structures).

Patients and methods: Two patients (67-year-old male and his 26-year-old son) with OI type I were included in this study. Slit lamp biomicroscopic and in vivo laser confocal microscopic examinations were performed for both patients. Central corneal thickness and central endothelial cell density were also measured.

Results: Although the corneas looked clear with normal endothelial density for both eyes in both patients, they were quite thin ( $386 \mu \mathrm{m}$ oculus dexter (OD) (the right eye) and $384 \mu \mathrm{m}$ oculus sinister (OS) (the left eye) in the father and $430 \mu \mathrm{m}$ OD and $425 \mu \mathrm{m}$ OS in the son). In both patients, slit lamp biomicroscopic and in vivo laser confocal microscopic examination showed similar results. Anterior corneal mosaics produced by rubbing the eyelid under fluorescein were completely absent in both eyes. In vivo laser confocal microscopy revealed an absent or atrophic Bowman's layer; a trace of a presumed Bowman's layer and/or basement membrane was barely visible with high intensity. Additionally, K-structures were completely absent in both eyes.

Conclusion: The absence of K-structures and fluorescein anterior corneal mosaics strongly suggested an abnormality of Bowman's layer in these OI patients.

Keywords: osteogenesis imperfecta, K-structure, confocal microscopy, Bowman's layer

\section{Introduction}

Osteogenesis imperfecta (OI) is a connective tissue disorder of the skeleton, ears, eyes, teeth, skin, and joints that is caused by an abnormality of type I collagen., ${ }^{1,2}$ Due to considerable phenotypic variability, Sillence et al developed a classification of OI subtypes: OI type I with blue sclera, perinatal lethal OI type II, also known as congenital OI, OI type III with a progressive deformation with a normal sclera, and OI type IV with a normal sclera. ${ }^{3}$ Aside from the blue sclera, the absence of Bowman's layer is also reported in OI. ${ }^{4}$

Previously, we demonstrated for the first time by using in vivo laser confocal microscopy that there are sub-Bowman's fibrous structures located just beneath subbasal nerves. ${ }^{5}$ These sub-Bowman's fibrous structures, also designated as K-structures, were 5 to $15 \mu \mathrm{m}$ in diameter and appeared to consist of many filaments. ${ }^{5}$ We have subsequently confirmed a strong association between K-structures and the presence/health of Bowman's layer. ${ }^{6,7}$

In this case report, we report for the first time the in vivo laser confocal microscopic findings of OI type I, and confirmed the associated abnormality of Bowman's layer and K-structures. 


\section{Patients and methods}

This study was approved by the Ethical Committee of Kanazawa University Graduate School of Medical Science and followed the tenets of the Helsinki Declaration. Two patients (a 67-year-old male and his 26-year-old son) with OI type I were included in this study. Slit lamp biomicroscopic, in vivo laser confocal microscopic examinations, and central endothelial cell density measurements were performed. Also, central corneal thickness was measured by OPTOVUE optical coherence tomography (Optovue, Inc., Fremont, CA, USA).

\section{In vivo laser confocal microscopy}

Informed consent was obtained after explaining the nature and possible consequences of microscopic study (such as superficial punctate keratopathy). A cornea specific, in vivo, laser confocal microscope (Heidelberg Retina Tomograph 2 Rostock Cornea Module, Heidelberg Engineering $\mathrm{GmbH}$, Heidelberg, Germany) was used to investigate all cell layers of the central cornea.

\section{Results}

A 67-year-old Japanese man with OI Type I, case 1, was referred to our clinic for ophthalmic evaluation. At the age of 62 , the patient had been treated with vitreous surgery, phacoemulsification, and intraocular lens implantation for a left rhegmatogenous retinal detachment. He had been deaf from the age of 24, and had no history of bone fractures. The patient used complete dentures, his height was $168 \mathrm{~cm}$ and his weight was $63 \mathrm{~kg}$. The past history of case 2, the son of case 1, is shown in Table 1. At the initial visit, bilateral blue sclera and iris atrophy was observed using slit lamp biomicroscopy in case 1 (Figure 1A and B). Although bilateral corneas were clear, the anterior corneal mosaic (ACM) usually apparent after eyelid rubbing with fluorescein staining was absent in both eyes (Figure 1C). The corneas were quite thin $(386 \mu \mathrm{m}$ oculus dexter (OD) (the right eye) and $384 \mu \mathrm{m}$ oculus sinister (OS) (the left eye) in Case 1 [Figure 1D] and $430 \mu \mathrm{m}$ OD and $425 \mu \mathrm{m}$ OS in Case 2). The diameters of the corneas in both patients were approximately $11 \mathrm{~mm}$. The endothelial cell density was 2,557 cells $/ \mathrm{mm}^{2}$ OD and 2,207 cells $/ \mathrm{mm}^{2}$ OS in Case 1, and 2,563 cells $/ \mathrm{mm}^{2}$ OD in case 2 (the data in OS was missing in case 2). No abnormal findings were noted by fundus examination except for chorioretinal scars after retinal detachment surgery in the left eye. The patient's corrected visual acuity in case 1 was 20/20 and his intraocular pressure was $10 \mathrm{~mm} \mathrm{Hg}$ in both eyes. The ocular findings of
Table I Phenotype of the patients with osteogenesis imperfecta

\begin{tabular}{|c|c|c|}
\hline Case & I father & 2 son \\
\hline Sex/age (years) & Male/67 & Male/26 \\
\hline Ol type & I & I \\
\hline Eye & B & B \\
\hline Sclera & Blue & Normal to grey \\
\hline $\mathrm{ACM}$ & Not present & Not present \\
\hline $\begin{array}{l}\text { K-structure (by } \\
\text { confocal microscopy)* }\end{array}$ & Not present & Not present \\
\hline Other ocular findings & $\begin{array}{l}\text { Clear but thin cornea } \\
\text { ( } 386 \mu \mathrm{m} \text { OD and } \\
384 \mu \mathrm{m} \text { OS). } \\
\text { Iris atrophy }\end{array}$ & $\begin{array}{l}\text { Clear but thin cornea } \\
(430 \mu \mathrm{m} \text { OD and } \\
425 \mu \mathrm{m} \text { OS) }\end{array}$ \\
\hline Bone fractures & No history & $\begin{array}{l}\text { Bone fractures in his } \\
\text { childhood }\end{array}$ \\
\hline Bone deformity & None & None \\
\hline Stature & $\begin{array}{l}\text { Normal (height of } \\
168 \mathrm{~cm} \text {, weight } \\
\text { of } 63 \mathrm{~kg} \text { ) }\end{array}$ & $\begin{array}{l}\text { Normal (height of } \\
174 \mathrm{~cm} \text {, weight } \\
\text { of } 67 \mathrm{~kg} \text { ) }\end{array}$ \\
\hline $\begin{array}{l}\text { Dentinogenesis } \\
\text { imperfecta }\end{array}$ & Complete dentures & Normal teeth \\
\hline Hearing loss & $\begin{array}{l}\text { Deaf from the } \\
\text { age of } 24\end{array}$ & $\begin{array}{l}\text { Deaf with otosclerosis } \\
\text { from the age of } 20\end{array}$ \\
\hline Other & Normal skin & Normal skin \\
\hline
\end{tabular}

Note: *K-structures are usually present in normal cornea by confocal microscopy. Abbreviations: ACM, anterior corneal mosaic; B, bilateral eye; Ol, osteogenesis imperfect; OD, oculus dexter (the right eye); OS, oculus sinister (the left eye).

case 2 are shown in Table 1. In both patients, keratoconus was ruled out by corneal topography.

\section{In vivo laser confocal microscopy}

Normal epithelial cell layer and subbasal nerves were observed in case 1 using in vivo laser confocal microscopy (Figure 2A and B). A trace of what was presumed to be Bowman's layer and/or basement membrane was barely visible, indicating that the Bowman's layer was missing or nearly atrophic (Figure 2C). The subepithelial stroma seemed normal (Figure 2D). However, K-structures usually seen between Bowman's layer and subepithelial stroma were completely absent. The keratocyte nuclei in the stroma (Figure 2E) and endothelial cells (Figure 2F) had a normal appearance. Similar findings of in vivo laser confocal microscopy were observed in case 2 .

\section{Discussion}

Four clinical types of OI are recognized and are caused by abnormalities of the $\alpha_{1}$ or $\alpha_{2}$ chains of type I collagen. ${ }^{1,2}$ In OI, there is a failure of type I collagen fibers to mature to their normal diameter. Mutations in the COL1A (17q21.31-q22) and COL1A2 genes (7q22.1) account for most cases in all four types. ${ }^{8} 9$ Patients with OI type I have a blue sclera; the blue coloration results from visualization of the underlying 

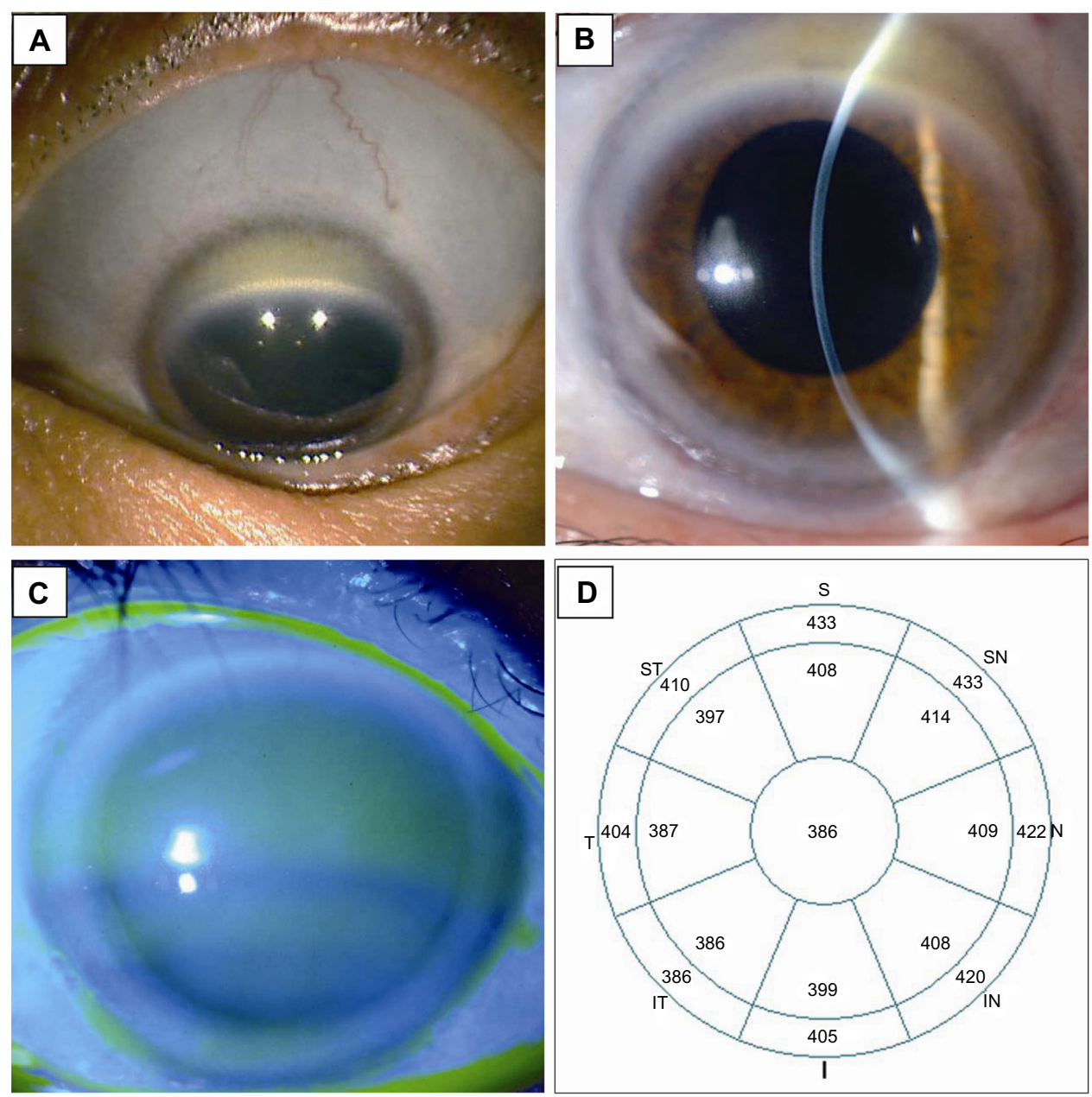

Figure I Slit lamp biomicroscopic photo and OPTOVUE optical coherence tomography analysis (Optovue, Inc., Fremont, CA, USA).

Notes: (A) Slit lamp biomicroscopic photo of the blue sclera in the left eye. Almost all sclera appears to be blue in color. (B) Slit lamp biomicroscopic photo of the right cornea. The cornea is clear. (C) After rubbing the right eye through the eyelid under fluorescein staining, no anterior corneal mosaic was seen. (D) Pachymetry map of the right cornea using OPTOVUE optical coherence tomography. The central cornea was as thin as $386 \mu \mathrm{m}$ in the right eye.

Abbreviations: S, superior; N, nasal; T, temporal; I, inferior; SN, superior nasal; ST, superior temporal; IN, inferior nasal; IT, inferior temporal.

choroid through a thin sclera. Ocular rigidity is reduced due to a thin sclera, which may confer a high risk of globe rupture. ${ }^{10}$ Interestingly, Bowman's layer may also be absent in OI. ${ }^{4}$ Therefore, we hypothesized that there might be some abnormality in Bowman's layer and/or adjacent superficial stroma in these OI patients.

Previously, we have speculated that K-structures (Figure 3) may correspond with anterior collagen fiber bundles running at the posterior surface of Bowman's layer based on light/electron microscopic observations ${ }^{11-13}$ and two photon generated second harmonic signal observations. ${ }^{14}$ We have subsequently reported that the overall distribution of K-structures in normal human corneas by in vivo laser confocal microscopy formed a net like pattern and corresponded quite well with the fluorescein ACM pattern observed using slit lamp biomicroscopy. ${ }^{6}$ These results support the hypothesis that the K-structures are the anterior collagen fiber bundles running at the posterior surface of Bowman's layer, and thus are the structural basis for ACM formation. Therefore, the presence of K-structures by in vivo laser confocal microscopy and fluorescein ACM by slit lamp biomicroscopy can be an indicator of the health of Bowman's layer. ${ }^{6,7}$ Furthermore, we have reported that both K-structures and ACM disappeared only after epipolis laser assisted in situ keratomileusis, in which Bowman's layer is destroyed, but not after laser assisted in situ keratomileusis in which Bowman's layer is preserved.?

In this study, we report a family with clinically diagnosed OI type I with blue sclera. Most notably, in vivo laser confocal microscopy showed Bowman's layer to be atrophic or nearly absent, with complete loss of K-structures in both patients. By slit lamp biomicroscopy, fluorescein ACM was 

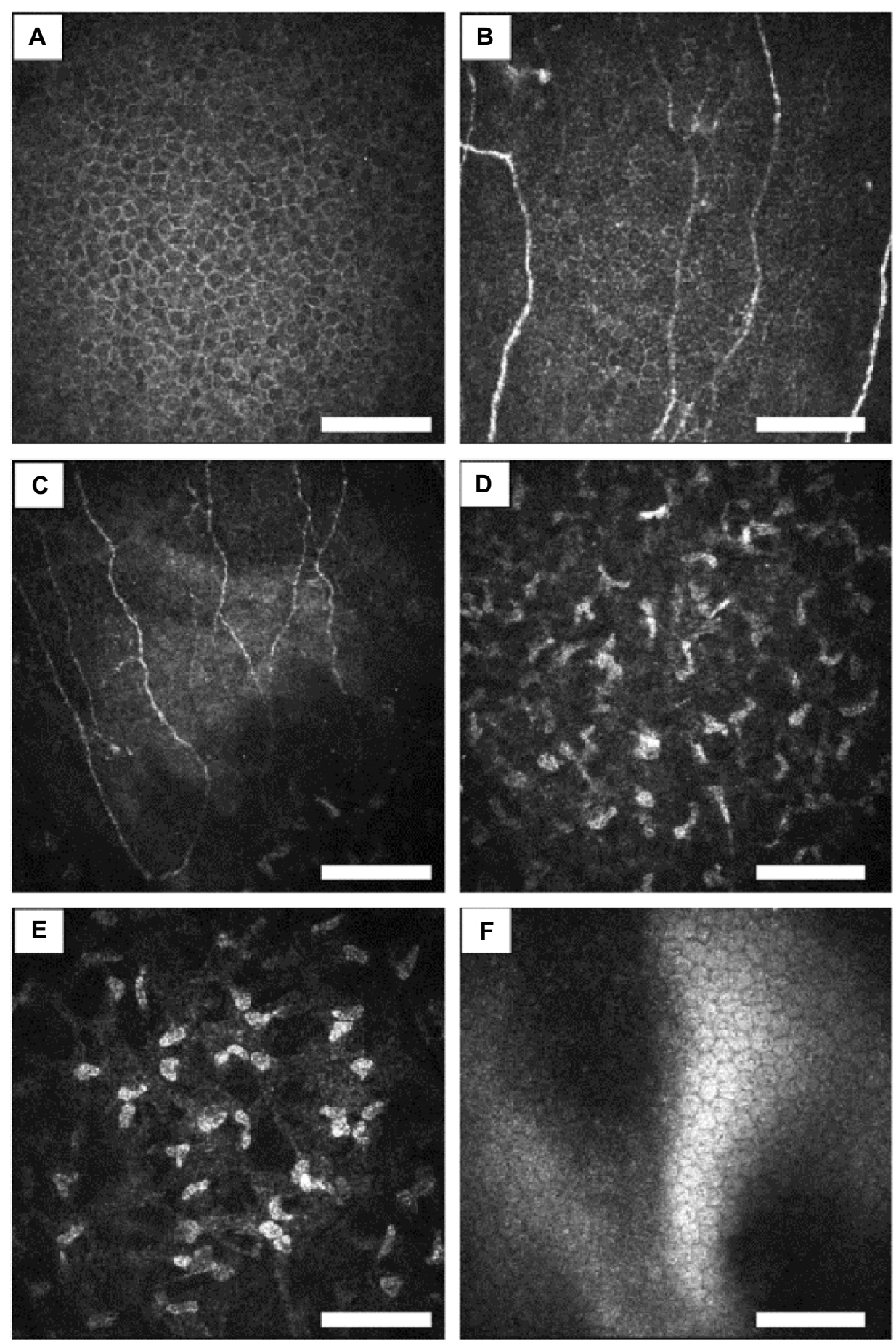

Figure 2 In vivo laser confocal microscopic analysis of the right eye in case I.

Notes: (A) A normal epithelial cell layer was seen. (B) Subbasal nerves running at the layer of basal epithelial cell layer. (C) Subbasal nerves running at the level of Bowman's layer. A trace of presumed Bowman's layer and/or basement membrane was barely visible, indicating that the Bowman's layer may be atrophic. (D) Subepithelial stroma had a normal appearance. However, K-structures (sub-Bowman's fibrous structures) usually seen between Bowman's layer and subepithelial stroma were completely absent. (E) Keratocyte nuclei at deep stroma seemed normal. (F) Endothelial cells seemed normal. Bar $=100 \mu \mathrm{m}$.

completely missing in both patients. These observations suggest an association of Bowman's layer abnormality and OI in these patients. Therefore, we surmise that Bowman's layer abnormality in OI may be associated with corneal stromal thinning. Also, loss of K-structure and absence of fluorescein ACM in suspected OI patients may suggest corneal complications and have supportive diagnostic value of OI. Further studies using larger groups of patients with different subtypes of OI are required to fully elucidate the abnormality of Bowman's layer in OI. 


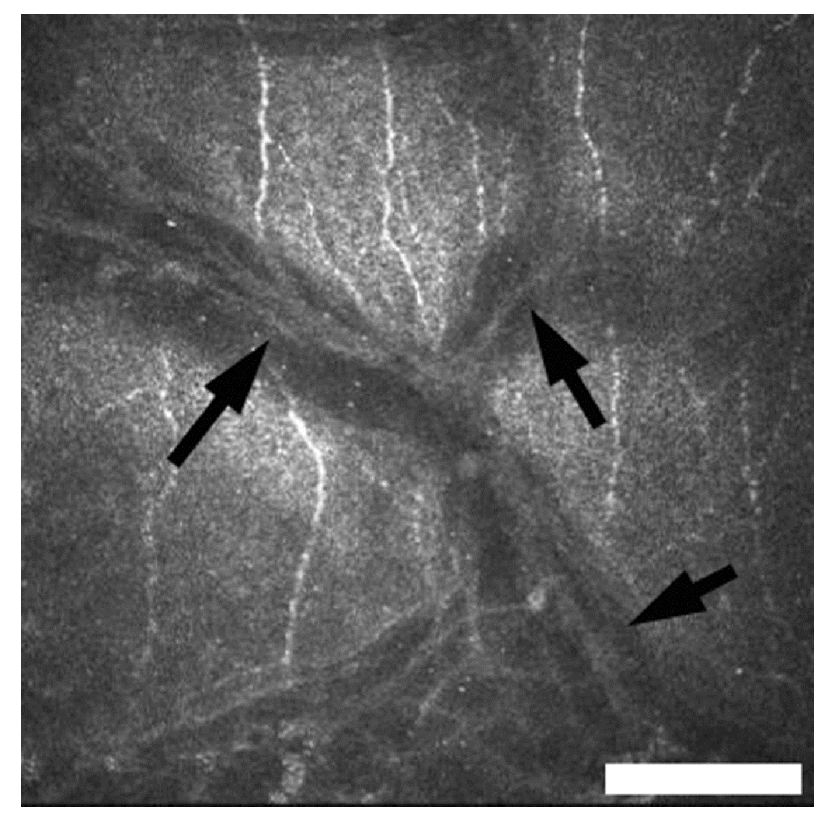

Figure 3 Normal K-structures (arrows) by in vivo laser confocal microscopy seen in a healthy volunteer (23-year-old female).

Note: $\mathrm{Bar}=100 \mu \mathrm{m}$.

\section{Disclosure}

None of the authors has any proprietary interest in any product mentioned in this article.

The corresponding investigator (AK) had full access to all data in the study and takes responsibility for the integrity of the data and the accuracy of the data analysis.

\section{References}

1. Sillence DO, Barlow KK, Garber AP, Hall JG, Rimoin DL. Osteogenesis imperfecta type II delineation of the phenotype with reference to genetic heterogeneity. Am J Med Genet. 1984;17(2):407-423.
2. Byers PH, Cole WG. Osteogenesis imperfect. In: Royce BM, Steinmann B, editors. Connective Tissue and its Heritable Disorders: Molecular, Genetic and Medical Aspects. New York: Wiley-Liss; 1993:385-430.

3. Sillence DO, Senn A, Danks DM. Genetic heterogeneity in osteogenesis imperfecta. J Med Genet. 1979;16:101-116.

4. Mietz H, Kasner L, Green WR. Histopathologic and electronmicroscopic features of corneal and scleral collagen fibers in osteogenesis imperfecta type III. Graefes Arch Clin Exp Ophthalmol. 1997;235: 405-410.

5. Kobayashi A, Yokogawa H, Sugiyama K. In vivo laser confocal microscopy of Bowman's layer of the cornea. Ophthalmology. 2006;113 2203-2208.

6. Yokogawa H, Kobayashi A, Sugiyama K. Mapping of normal corneal $\mathrm{K}$-structures by in vivo laser confocal microscopy. Cornea. 2008;27: 879-883.

7. Yokogawa H, Kobayashi A, Tagawa K, Sugiyama K. In vivo laser confocal microscopic analysis of corneal K-structures after keratorefractive surgery (LASIK and epi-LASIK). Ophthalmic Surg Lasers Imaging. 2010;41:494-498.

8. Marini JC, Grange DK, Gottesman GS, Lewis MB, Koeplin DA. Osteogenesis imperfecta type IV: detection of a point mutation in one alpha-1(I) collagen allele (COL1A1) by RNA/RNA hybrid analysis. J Biol Chem. 1989;264:11893-11900.

9. Wenstrup RJ, Cohn DH, Cohen T, Byers PH. Arginine for glycine substitution in the triple-helical domain of the products of one alpha-2(I) collagen allele (COL1A2) produces the osteogenesis imperfecta type IV phenotype. J Biol Chem. 1988;263:7734-7740.

10. Kaiser-Kupfer MI, McCain L, Shapiro JR, Podgor MJ, Kupfer C, Rowe D Low ocular rigidity in patients with osteogenesis imperfecta. Invest Ophthalmol Vis Sci. 1981;20:807-809.

11. Hogan MJ, Alvarado JA, Weddell JE. Histology of the Human Eye An Atlas and Textbook. Philadelphia: WB Saunders; 1971:55-111.

12. Komai Y, Ushiki T. The three-dimensional organization of collagen fibrils in human cornea and sclera. Invest Ophthalmol Vis Sci. 1991;32: 2244-2258.

13. Smolek MK, Klyce SD. Cornea. In: Tasman W, Jaeger EA, editors. Duane's Foundation of Clinical Ophthalmology. Volume 1. Ocular Anatomy, Embryology, and Teratology. Philadelphia: Lippincott Williams \& Wilkins; 2006.

14. Morishige N, Petroll WM, Nishida T, Kenney MC, Jester JV. Noninvasive corneal stromal collagen imaging using two-photongenerated second-harmonic signals. J Cataract Refract Surg. 2006;32: $1784-1791$
Clinical Ophthalmology

\section{Publish your work in this journal}

Clinical Ophthalmology is an international, peer-reviewed journal covering all subspecialties within ophthalmology. Key topics include: Optometry; Visual science; Pharmacology and drug therapy in eye diseases; Basic Sciences; Primary and Secondary eye care; Patien Safety and Quality of Care Improvements. This journal is indexed on

\section{Dovepress}

PubMed Central and CAS, and is the official journal of The Society of Clinical Ophthalmology (SCO). The manuscript management system is completely online and includes a very quick and fair peer-review system, which is all easy to use. Visit http://www.dovepress.com/ testimonials.php to read real quotes from published authors. 